$\xi=-1$ 圆

\title{
Experimental Testing Results of Reinforced Concrete Beams Under Biaxial Bending
}

\author{
Andriy Pavlikov ${ }^{1}$, Marta Kosior-Kazberuk ${ }^{2}$, Olha Harkava ${ }^{3}$ * \\ ${ }^{I}$ Poltava National Technical Yuri Kondratyuk University, Ukraine \\ ${ }^{2}$ Bialystok University Of Technology, Poland \\ ${ }^{3}$ Poltava National Technical Yuri Kondratyuk University, Ukraine \\ *Corresponding Author E-Mail:Olga-Boiko@Ukr.Net
}

\begin{abstract}
The experimental tests data of reinforced concrete beams of a rectangular profile made of heavy concrete on pure biaxial bending are presented. The inclination angle of the external load plane to the vertical axis of inertia of the section varied in the range from $0^{\circ}$ to $20^{\circ}$. The tests were conducted to study the work of the biaxial bended elements under load and to verify the developed method for strength analysis of such elements. It has been established that the order of changing the neutral axis position in the section of the biaxial bending beams in the loading process depends primarily on the relative disposition of the external load plane and the resultant in the tensioned reinforcement. It has been confirmed that the ultimate compressed fibrous strains of concrete depend not on the shape of the section, but on the shape of the concrete compressed zone. The results of the tests have good correspondence with theoretical calculations, which proves the expediency of using the developed engineering method for the strength analysis.
\end{abstract}

Keywords: beam; biaxial bending; reinforced concrete; strength; test.

\section{Introduction}

A significant part of reinforced concrete elements works under conditions of biaxial bending without axial force. These elements include: precast girders, laid along the upper chords of trusses and lattice girders; crane beams; horizontal elements of half-timbered frames; side elements of shells, elements of bridges, flight stairs and underground structures; supports and girders of transport galleries, overpasses and pipelines; foundation and framing beams, which are used in seismic regions and under complex geological conditions; other structures and their elements.

In addition, a large number of structures designed to operate under conditions of simple bending also experience biaxial bending to some extent due to various unforeseen factors and causes. Specified reasons can be conditionally divided into groups, which include the following: technological inaccuracies in the structures making; inaccuracies in the structures assembling; seismic loads; local destruction of reinforced concrete structures; changing crosssections of elements during the reconstruction of buildings and structures; uneven temperature effect; heterogeneity of reinforced concrete. The above-mentioned factors make it impossible to realize a simple bending in practice.

Thus, at the present stage of the evolution of the reinforced concrete theory, the development of a new method for analysis of the section of flexural elements at ultimate limit state must be based on the analysis of biaxial bended elements, since it is impossible to avoid biaxial bending in reality.

However, it should be noted that the analysis of the section under biaxial bending based on Eurocode 2 is a rather complicated task from the engineering point of view. Therefore, in connection with the widespread distribution of biaxial bended reinforced concrete elements, the designers face the problem regarding its analysis at ultimate limit state.

Developed by the authors of this research the engineering method for designing sections of reinforced concrete elements subjected to biaxial bending simplifies the calculating procedure, but requires experimental verification. In this case, not only the value of the failure load, but also other parameters should be taken into account, which uniquely characterize the mode of deformation of the normal section of biaxial bended elements. These are the inclination angle $\theta$ of the neutral axis to the horizontal axis of the section inertia, the neutral axis depth $\mathrm{X}$ and the strain $\varepsilon_{\mathrm{c}(1)}$ of the concrete of the most compressed fibre.

Experimental researches of the strength of biaxially deformed reinforced concrete elements, carried out recently [ $1-7]$, relate primarily to the structures subjected to axial force and biaxial bending. This is due to the fact that biaxial bending with axial force of reinforced concrete elements is generally considered to be a general form of biaxial deformation [8]. In developing the methods of the section analysis, it is assumed that the biaxial bending without axial force is a special case of biaxial deformation. That is, the method of the analysis of the section under biaxial bending without axial force can be obtained from the general method of analysis, assuming the value of the longitudinal force to be zero. Such an approach is unacceptable for experimental tests, in contrast to theoretical researches. Consequently, the amount of experimental data that characterize the strength and parameters of the deformation mode of reinforced concrete beams under biaxial bending is not sufficient to verify the developed calculation method. Although some data are encountered in the literature, either they are out of date or do not cover the whole spectrum of the investigated factors or the authors use the data of numerical experiments [9-12]. 


\section{Construction of Experimental Samples and their Manufacture Technology}

In order to determine the strength of reinforced concrete beams subjected to biaxial bending and to study their work under load, and to obtain experimental values of the parameters characterizing the deformation mode of the beam during structural failure, experimental tests were carried out. The influence of the angle $\beta$ of inclination of the external load plane on the vertical axis of inertia of the cross section, as well as the number and location of the principal reinforcement on the strength of the beams, the position of the neutral axis, and the fibre strains of the concrete of the compressed zone were studied.

Experimental beams (Fig. 1) are divided into four series, depending on the number and location of the longitudinal principal reinforcement.

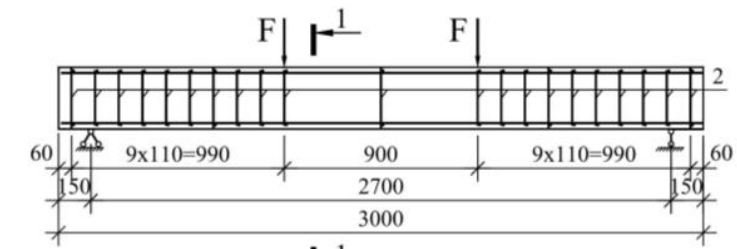

$1+1$

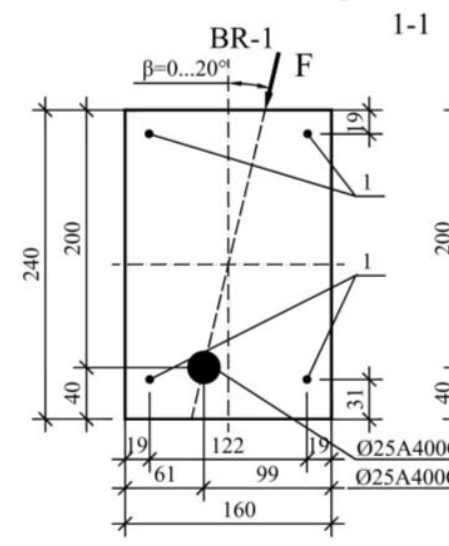

BR-3
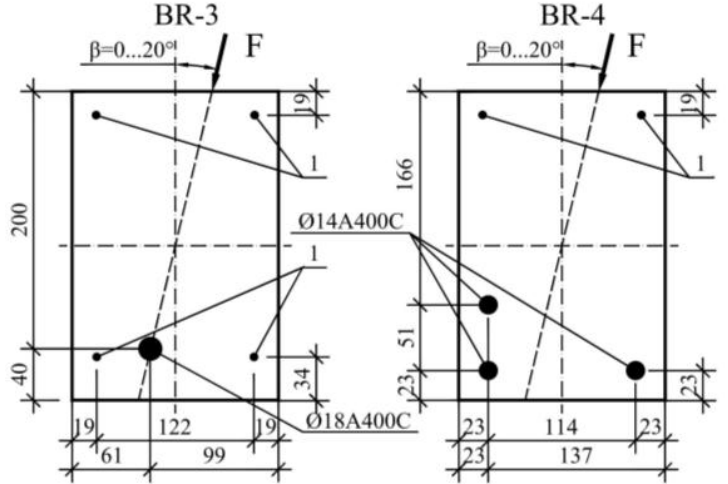

Fig. 1: The construction of experimental beam samples: 1 - longitudinal structural reinforcement $\left(\varnothing 6 \mathrm{~A} 240 \mathrm{C} ; \mathrm{f}_{\mathrm{yk}},=357 \mathrm{MPa} ; \mathrm{E}_{\mathrm{s}}=200000 \mathrm{MPa}\right)$ 2 - shear reinforcement $\left(2 \varnothing 6 \mathrm{~A} 240 \mathrm{C} ; \mathrm{f}_{\mathrm{yk}},=357 \mathrm{MPa} ; \mathrm{E}_{\mathrm{s}}=200000 \mathrm{MPa}\right)$

In order to determine the physicomechanical characteristics of the reinforcement, the specimens $(1=600 \mathrm{~mm})$ were cut from each reinforcing bar during the fabrication of cages, which were then tested for tension on the UIM-50 press. As a result of the tests, the modulus of elasticity $\mathrm{E}_{\mathrm{s}}$ and the characteristic yield strength of the reinforcing steel $\mathrm{f}_{\mathrm{yk}}$ have been determined (Table 1).

To determine the properties of concrete, compression tests were carried out on concrete prisms $(150 \times 150 \times 600 \mathrm{~mm})$ and cubes $(150 \times 150 \times 150 \mathrm{~mm})$ made of a concrete mix that was used for beams. The tests were carried out on a hydraulic press 2PG-125. As a result of the tests, the secant modulus of elasticity of concrete $\mathrm{E}_{\mathrm{cm}}$ and mean value of concrete prismatic compressive strength $\mathrm{f}_{\mathrm{cm}, \text { prism }}$ have been determined (Table 1).
Table 1: Characteristics of experimental beam samples

\begin{tabular}{|c|c|c|c|c|c|c|}
\hline \multirow{2}{*}{$\begin{array}{l}\text { Sample } \\
\text { code }\end{array}$} & \multirow{2}{*}{$\begin{array}{l}\text { Inclina- } \\
\text { tion } \\
\text { angle of } \\
\text { the load } \\
\text { plane, } \beta^{\circ}\end{array}$} & \multicolumn{2}{|c|}{$\begin{array}{l}\text { Characteristics of } \\
\text { concrete }\end{array}$} & \multicolumn{3}{|c|}{$\begin{array}{l}\text { Characteristics of principal } \\
\text { longitudinal reinforcement }\end{array}$} \\
\hline & & $\begin{array}{l}\mathrm{f}_{\mathrm{cm}, \text { prism }} \\
\mathrm{MPa}\end{array}$ & $\begin{array}{l}\mathrm{E}_{\mathrm{cm}} \\
\mathrm{MPa}\end{array}$ & $\begin{array}{l}\text { Diameter, } \\
\text { class }\end{array}$ & $\begin{array}{l}\mathrm{f}_{\mathrm{yk}} \\
\mathrm{MPa}\end{array}$ & $\begin{array}{l}\mathrm{E}_{\mathrm{s}} \\
\mathrm{MPa}\end{array}$ \\
\hline BR-1-1 & 0 & 25 & 24734 & $1 \varnothing 25 \mathrm{~A} 400 \mathrm{C}$ & 379 & 200000 \\
\hline BR-1-2 & 6.40 & 25 & 24734 & $1 \varnothing 25 \mathrm{~A} 400 \mathrm{C}$ & 379 & 200000 \\
\hline BR-1-3 & 10 & 25 & 24734 & $1 \varnothing 25 \mathrm{~A} 400 \mathrm{C}$ & 379 & 200000 \\
\hline BR-1-4 & 13.36 & 25 & 24734 & $1 \varnothing 25 \mathrm{~A} 400 \mathrm{C}$ & 379 & 200000 \\
\hline BR-1-5 & 20 & 22 & 23576 & $1 \varnothing 25 \mathrm{~A} 400 \mathrm{C}$ & 379 & 200000 \\
\hline BR-2-1 & 13.36 & 14 & 17992 & $1 \varnothing 25 \mathrm{~A} 400 \mathrm{C}$ & 379 & 200000 \\
\hline BR-2-2 & 20 & 14 & 17992 & $1 \varnothing 25 \mathrm{~A} 400 \mathrm{C}$ & 379 & 200000 \\
\hline BR-3-1 & 0 & 22 & 23576 & 1Ø18A400C & 542 & 200000 \\
\hline BR-3-2 & 13.36 & 22 & 23576 & 1Ø18A400C & 542 & 200000 \\
\hline BR-3-3 & 20 & 22 & 23576 & $1 \varnothing 18 \mathrm{~A} 400 \mathrm{C}$ & 542 & 200000 \\
\hline BR-4-1 & 0 & 21 & 20921 & $3 \varnothing 14 \mathrm{~A} 400 \mathrm{C}$ & 581 & 200000 \\
\hline BR-4-2 & 6.40 & 21 & 20921 & $3 \varnothing 14 \mathrm{~A} 400 \mathrm{C}$ & 581 & 200000 \\
\hline BR-4-3 & 10 & 21 & 20921 & 3Ø14A400C & 581 & 200000 \\
\hline BR-4-4 & 13.36 & 21 & 20921 & $3 \varnothing 14 \mathrm{~A} 400 \mathrm{C}$ & 581 & 200000 \\
\hline BR-4-5 & 20 & 14 & 17992 & $3 \varnothing 14 \mathrm{~A} 400 \mathrm{C}$ & 581 & 200000 \\
\hline
\end{tabular}

\section{Experimental Tests Procedure}

The support conditions of the beams were realized according to the scheme shown in Fig. 2. The distance between the supports for all samples was $2.7 \mathrm{~m}$. The external load was applied in the form of two concentrated forces in the middle third of the span. Longitudinal strains of concrete and reinforcement were measured in the middle section of the beam using resistance strain gages with base $50 \mathrm{~mm}$ for concrete and $20 \mathrm{~mm}$ for reinforcement (Fig. 2).
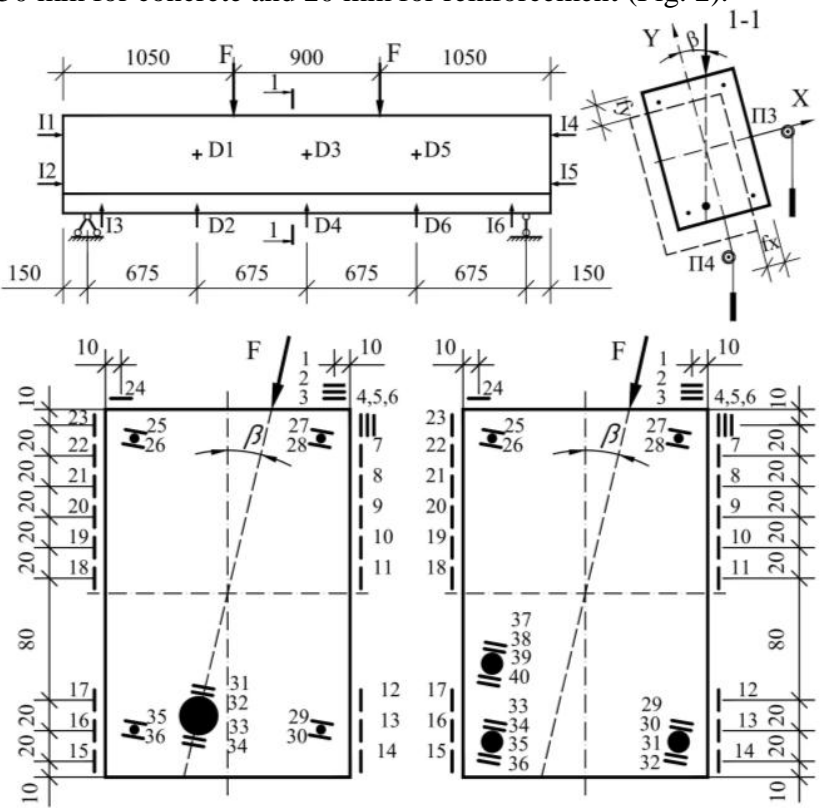

Fig. 2: The diagram of supporting, loading and placement of instruments for measuring deflections of the beams and strains of concrete and reinforcement: I - dial gauge indicators; D - deflectometers; 1 . . 36 - resistance strain gages.

Loading was carried out in steps of $10 \%$ of the failure load. At the beginning of the loading, the value of the steps was $5 \%$ of the failure load. After the first cracks appearance, further loading was conducted with a constant rate of concrete strain of the most compressed rib of the beams.

During the test, the beams were brought to failure (Fig. 3), which was characterized by a continuous increase of deflections, development and opening of cracks in tensioned concrete at the maximum load achieved. After the perception of the failure load maximum value by the samples, a further increase of concrete strains occurred in the most compressed rib of the beams. At the same time, there was a short-term gradual decrease in the load. 

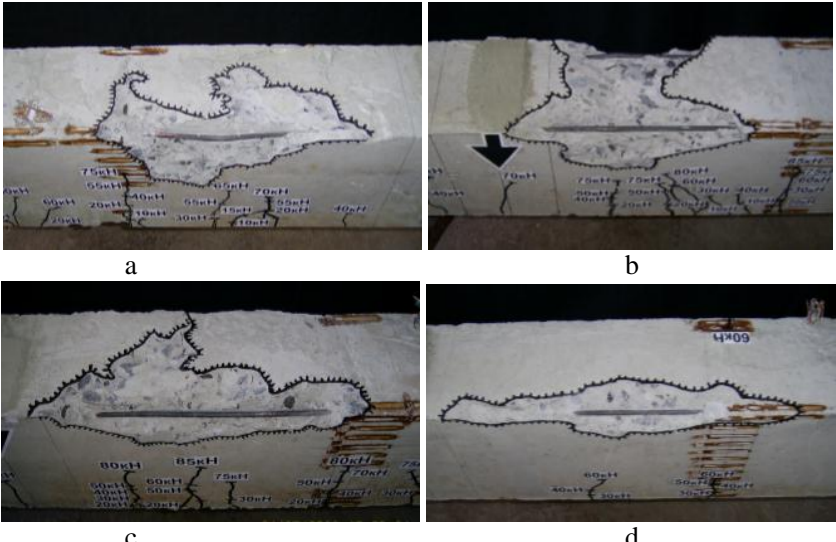

Fig. 3: A compressed zone of experimental beams after failure: a - BP-1-1 $\left(\beta=0^{\circ}\right) ; b-B R-1-3\left(\beta=10^{\circ}\right) ; c-B R-1-4\left(\beta=13.36^{\circ}\right) ; d-B R-1-5\left(\beta=20^{\circ}\right)$.

\section{Forms of the Compressed Zone of the Ex- perimental Beams Section}

The position of the neutral axis in the cross section of experimental beams at each stage of loading was determined by means of diagrams of the relative deformations of the reinforcement and concrete, constructed from the data of the strain gauges.

As shown in Fig. 4, the position of the neutral axis in the normal section of the beam is characterized by two parameters: the inclination angle $\theta$ of the neutral axis and the neutral axis depth $X$. The compressed zone of concrete in the normal section of experimental beams under biaxial bending took the form of a rectangle, a trapezoid and a triangle.

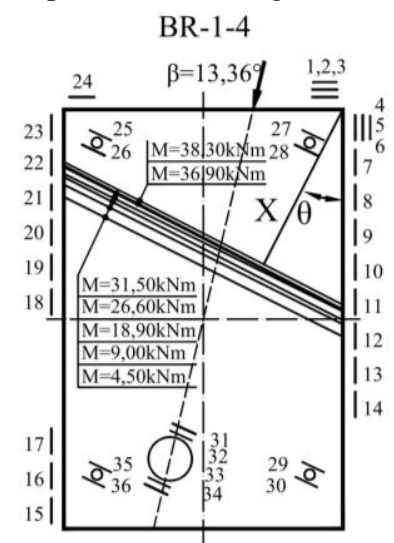

BR-1-1

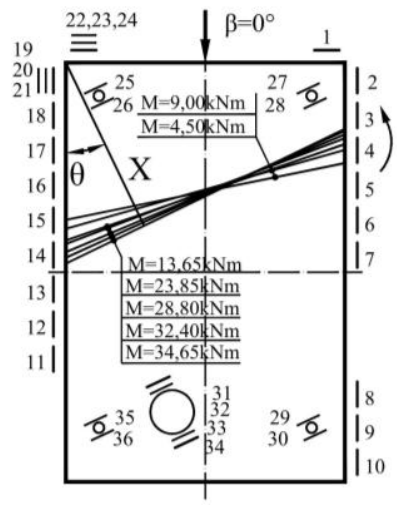

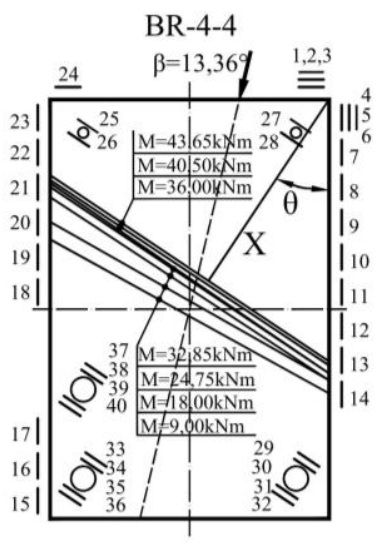

BR-1-5

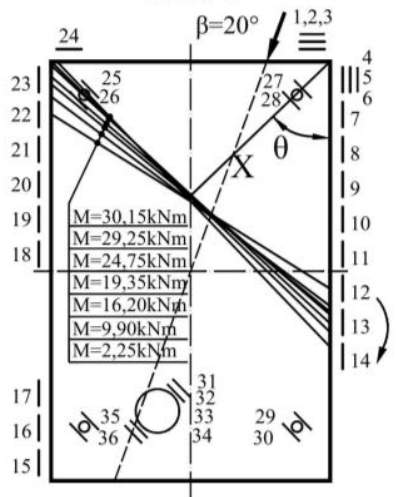

Fig. 4: Moving and rotating the neutral axis during the loading process (arrows indicate the direction of rotation): $\mathrm{M}=$ external bending moment.

There was a parallel displacement of the neutral axis towards the most compressed rib in the beams BR-1-4 and BR-4-4 at all loading stages (Fig. 4). In this case, the plane of action of the external load passed through the application point of the resultant in the tensioned reinforcement. In other beams, during the loading pro- cess, the neutral axis was rotated (Fig. 4) and the direction of its rotation depended on the location of the load plane about to the application point of the resultant in the tensioned reinforcement. In the case of the load at a small angle $\beta$, that is, when the force plane passes to the right of the application point of the resultant in the tensioned reinforcement, the neutral axis turns counter clockwise as the load increases (Fig. 4, BR-1-1). The rotation of the neutral line in a clockwise direction occurred when the plane of action of the external load was located to the left of the application point of the resultant in the tensioned reinforcement (Fig. 4, BR-1-5).

\section{Parameters of the Neutral Axis Position}

To analyse the influence of various factors on the placement of the neutral line in the section of experimental beams, the diagrams of the dependences $\theta$ on the loading level M / Mu have been plotted (Fig. 5).

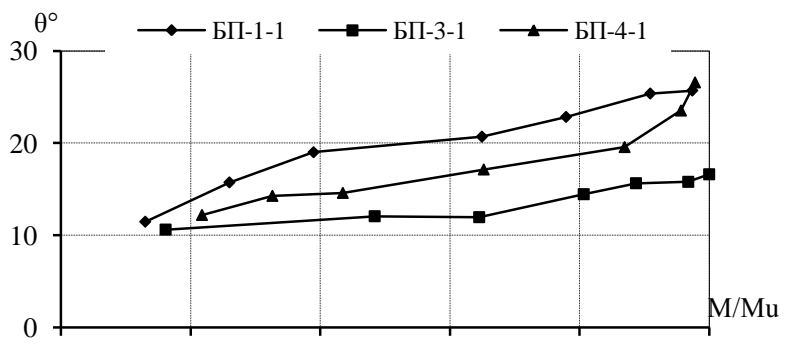

Основной Основной Основной Основной Основной Основной

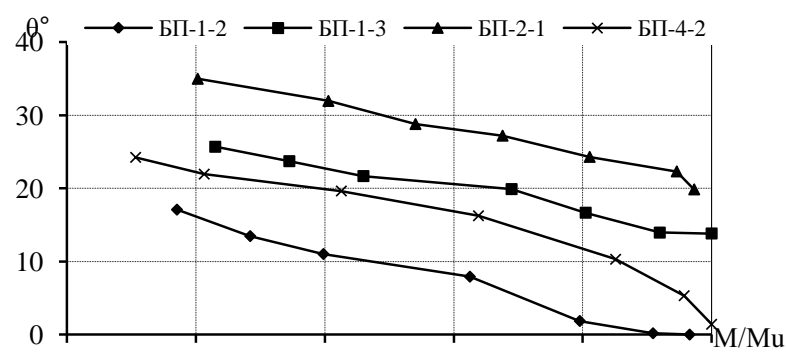

Основной Основной Основной Основной Основной Основной b

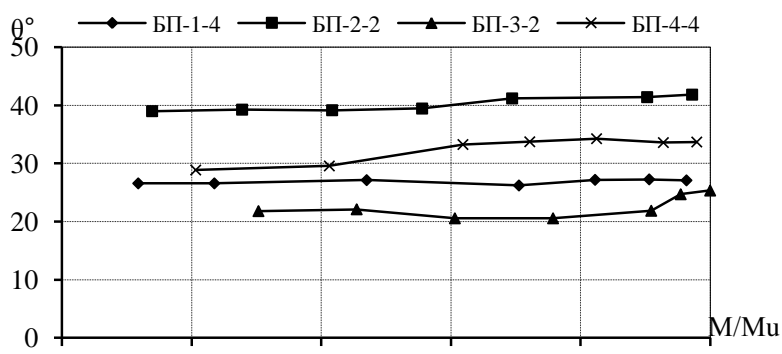

Основной Основной Основной Основной Основной Основной c

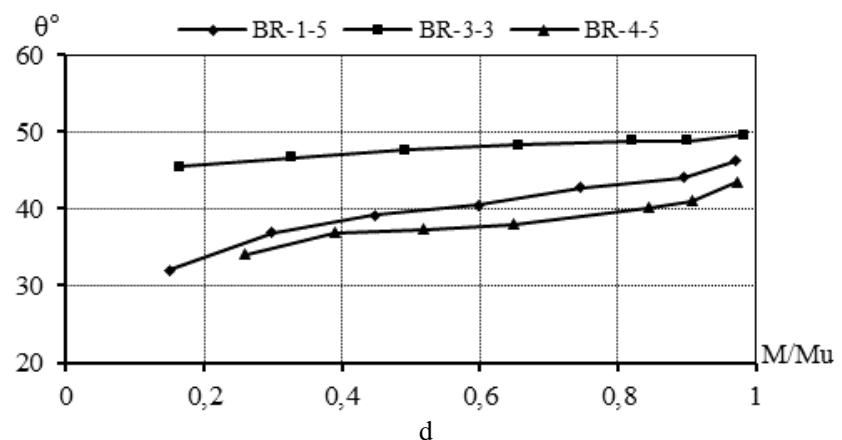

Fig. 5: Diagrams of changing the inclination angle $\theta$ of the neutral axis during the loading process: $\mathrm{Mu}=$ ultimate bending moment. 
From Fig. 5 it can be seen that changing of the inclination angle $\theta$ of the neutral axis was different for various beams with load increasing. In the beams that were tested at the zero value of the inclination angle $\beta$ of the load plane, the angle $\theta$ was nonzero (Fig. 5, a; Fig. 4, BR-1-4). That is, the beam under an axisymmetric load experienced the phenomenon of provoked biaxial bending that arose from noncoincidence of the application point of the resultant in the tensioned reinforcement with the external load plane. With an increase in the load, the absolute values of the angle $\theta$ grew (Fig. 5, a), that is, the neutral axis turned counter clockwise. A decrease of the neutral axis inclination angle of during the loading with rotation of the neutral axis counter clockwise was observed in all other beams in which the external load plane passed to the right of the application point of the resultant in the of the tensioned reinforcement (Fig. 5, b). At $\beta=6 \cdot 40^{\circ}$ a characteristic case of biaxial bending is obtained - an analogue of a simple bending is obtained, in which the shape of the compressed concrete zone was rectangular.

The diagrams in Fig. 5, c show the case when the action plane of the external bending moment passed through the application point of the resultant in the tensioned reinforcement, while the angle $\theta$ remained almost unchanged throughout the entire loading interval. The tendency to increase the angle $\theta$ with increasing load was observed in the tested beams at $\beta=20^{\circ}$ (Fig. 5, d).

Thus, the character of the change of the neutral axis inclination angle $\theta$ during loading is significantly affected by the relative disposition of the external and internal load planes, which is determined by the angle $\beta$ value and the location of the application point of the resultant in the tensioned reinforcement.

From the analysis of the neutral axis behaviour (Fig. 6), it is obvious that the neutral axis depth $\mathrm{X}$ of the biaxial reinforced concrete beam with increasing load level over the entire loading range tended to increase or decrease depending on the angle $\beta$.
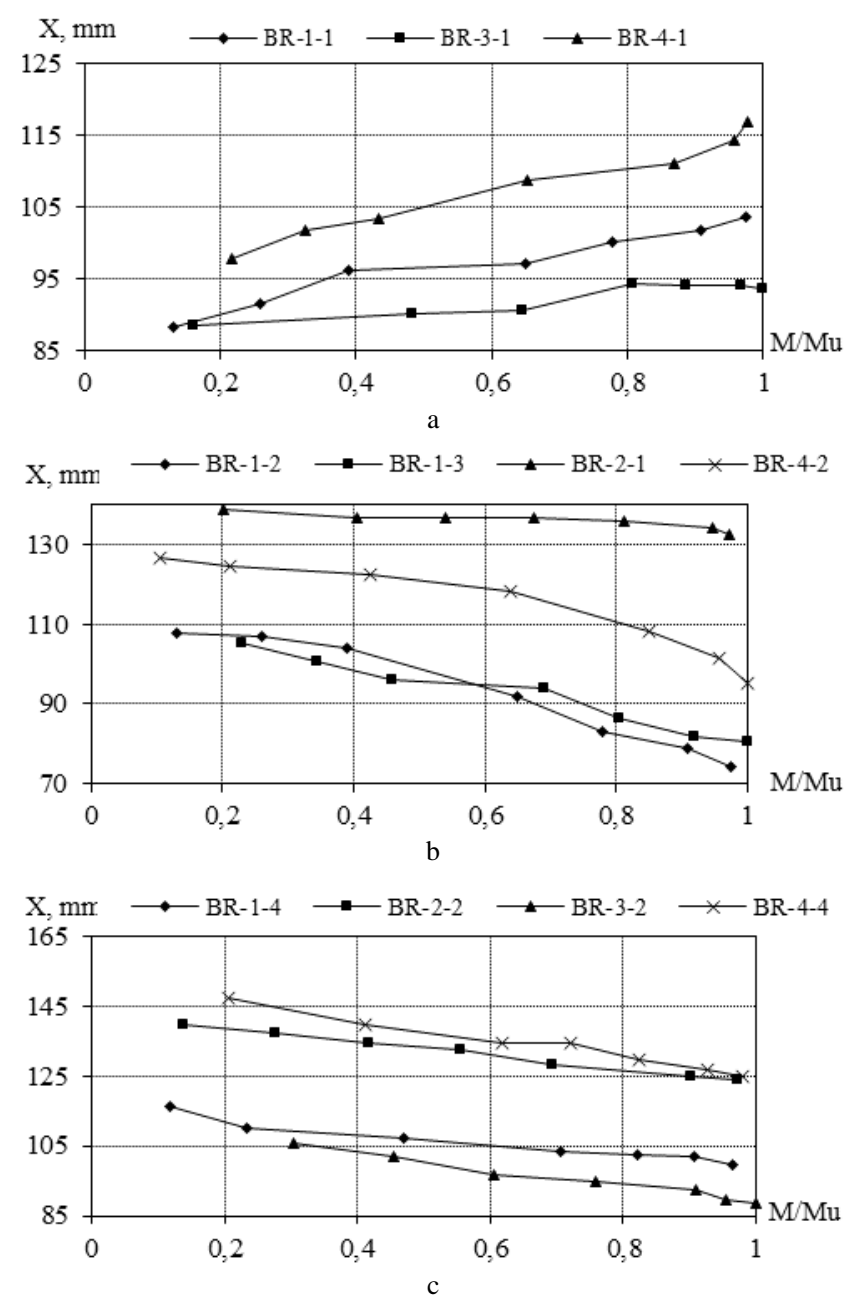

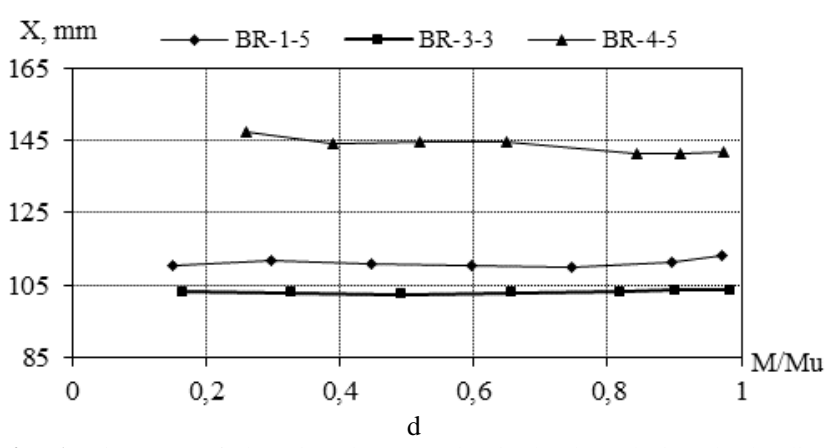

Fig. 6: Diagrams of changing the neutral axis depth $X$ during the loading process: $\mathrm{Mu}=$ ultimate bending moment.

The neutral axis depth $\mathrm{X}$ increased in the beams, which were tested at $\beta=0^{\circ}$ (Fig. 6, BR-1-1). In all other beams, the neutral axis depth throughout the load interval decreased. Both the decrease and the increase of the neutral axis depth passed most intensively to the loading level of $0.4 \mathrm{M} / \mathrm{Mu}$ and after reaching $0.6 \mathrm{M} / \mathrm{Mu}$. At an interval of $0.4-0.6 \mathrm{M} / \mathrm{Mu}$, the intensity of change in $\mathrm{X}$ was low. It should also be noted that at a large inclination angle of the force plane $\beta=20^{\circ}$, the decrease in $X$ was slight throughout the entire loading interval (Fig. 6, BR-1-5). The total decrease in the neutral axis depth from the start of loading to failure averaged $16 \%$ (for beams tested at $\beta=0^{\circ}$ ), and the increase in $X$ for all other beams varied from $44 \%$ to $3 \%$ with the increase in the angle $\beta$ from $6,40^{\circ}$ to $20^{\circ}$.

\section{Strains of Concrete and Reinforcement of The Experimental Beams}

During the experimental tests of the beams, considerable attention was paid to determining the fibrous strains of the compressed concrete area. From the very beginning of the loading, the maximum strains of the concrete were observed in the most compressed rib of the biaxial bended beams, and at the moment of failure they reached the ultimate values. After the element perceived the maximum value of the destructive load, a short-term decrease of the load took place with a simultaneous increase in the strains of concrete in the extreme section fibre.

This regularity can be traced on the diagrams of the dependence of fibrous concrete strains $\varepsilon_{\mathrm{c}(1)}$ of the most compressed rib in the beam on the external bending moment $\mathrm{M}$, ploted from the results of experimental tests (Fig. 7). Having analyzed the indicated diagrams it can be stated that beams, like prism samples, have stressstrain diagrams. With the help of such diagrams, it is possible to determine the ultimate values $\varepsilon_{\text {cu }}$ of fibrous compressive strains in the concrete in beams under biaxial bending, and the corresponding values $\mathrm{M}_{\mathrm{u}}$ of bending moments can be taken as those that determine the carrying capacity of an biaxial bended reinforced concrete element at the time of its failure.

The analysis of these diagrams shows that at the same inclination angle $\beta$ of the load plane, the ultimate strains of the beams depend on the number and class of the principal reinforcement. Thus, in the beams of the BR-3 series, which have the smallest area of the principal reinforcement, and, consequently, the minimum value of the resultant in the tensioned area at the moment of failure, the strains $\varepsilon_{\text {cu }}$ (Fig. 8) reach lower values than those of other beams. It should be noted that the beams of the BR-1 and BR-4 series are reinforced in such a way that, with an almost identical principal reinforcement area, the number of reinforcing bars in the beams is different. In this case, three $\varnothing 14$ bars of the BR- 4 beams are disposed so that the application point of the resultant in the tensioned reinforcement coincides with the point of application of the resultant for the beams BR-1 reinforced with one $\varnothing 25$ bar. As can be seen from the diagrams in Fig. 7 , the nature of the $M-\varepsilon_{\mathrm{c}(1)}$ dependences at identical angles $\beta$ for the aforementioned series of beams does not differ. However, the ultimate fibrous concrete strains of beams of the BR-4 series reach high values, which is 
explained by the higher yield strength of the principal reinforcement, and hence the greater value of the resultant in the tensioned area at the time of failure.

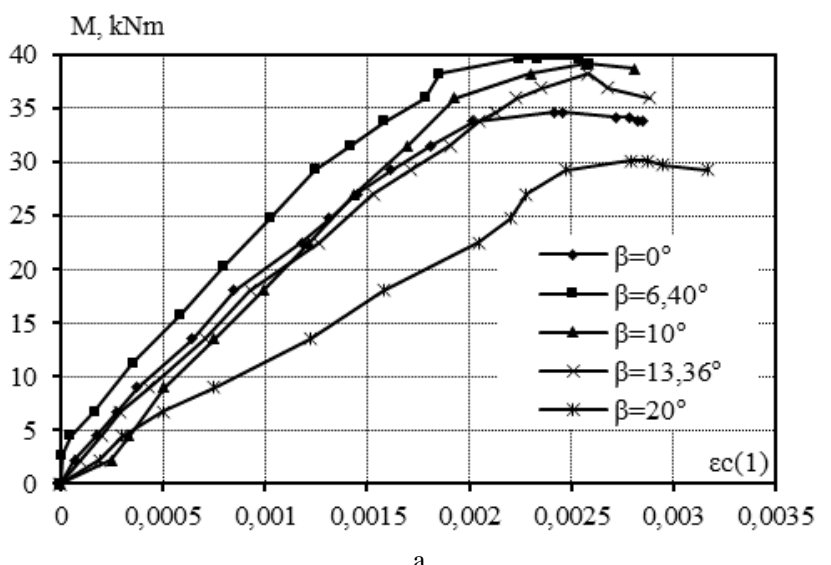

$\mathrm{M}, \mathrm{kNm}$

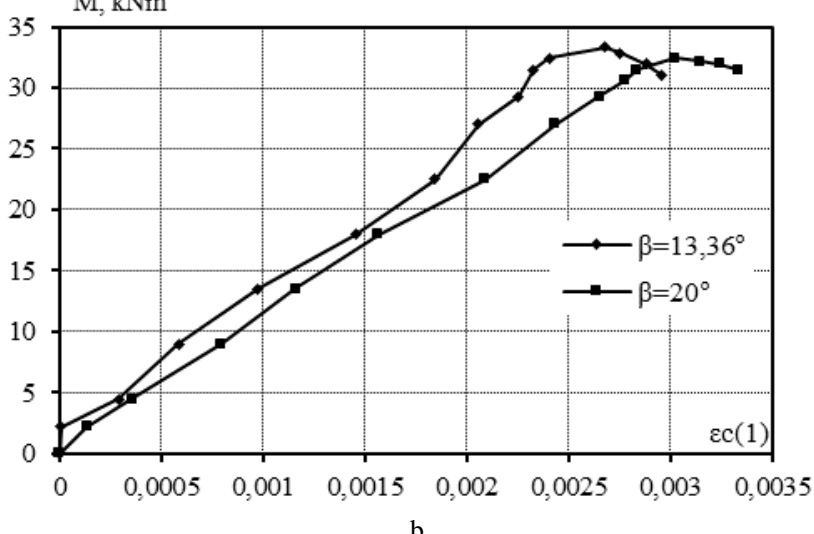

$\mathrm{M}, \mathrm{kNm}$
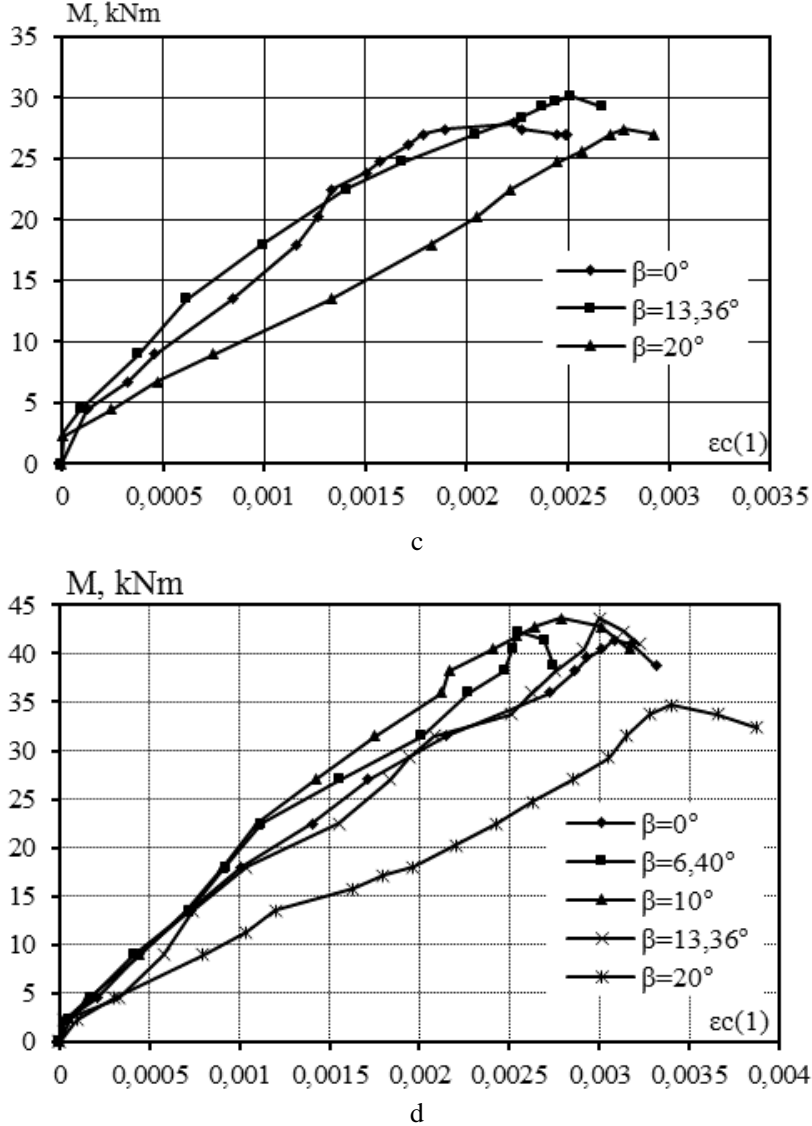

Fig. 7: Diagrams of the $M-\varepsilon_{\mathrm{c}(1)}$ dependence for the experimental beams: $\mathrm{a}$ - series BR-1; b - series BR-2; c-series BR-3; d-series BR-4.

That is, it can be argued that an increase in the number and class of principal reinforcement increases the value of the ultimate fi- brous compressive concrete strains in the composition of biaxial bended reinforced concrete beams.

A comparison of the $\mathrm{M}-\varepsilon_{\mathrm{c}(1)}$ curves plotted for twin beams with a single reinforcement of the BR-1 series (Fig. 7, a) and discretely reinforced series BR-4 (Fig. 7, d) indicates that the ultimate strains in the concrete in the most compressed rib increase with increasing angle of inclination $\beta$ of the external load plane. The only exceptions are the beams tested at $\beta=0^{\circ}$.

However, it should be noted here that all the beam samples are reinforced in such a way that the gravity center of the principal reinforcement is offset relative to the vertical symmetry axis of the section. That is, the axisymmetric loading is not a guarantee of simple bending, but, on the contrary, leads to the rotation of the neutral axis counterclockwise with the formation of a trapezoidal compressed concrete area, that is, causes the phenomenon of provoked biaxial bending. Thus, the ultimate fibrous strains in the concrete of the compressed area depend directly not only on the application angle $\beta$ of the external load, but also on the location of the principal reinforcement.

Considering the character of the $\mathrm{M}-\varepsilon_{\mathrm{c}(1)}$ dependences, it can be noted the following character of the effect of the angle $\beta$ on the curvature of the diagrams: with an increase in $\beta$ to $20^{\circ}$, the concrete deformation of the most compressed rib occurs more intensively, as indicated by the rectification of the diagrams $\mathrm{M}-\varepsilon_{\mathrm{c}(1)}$. The reason for this phenomenon is that when converting a rectangular shape of a compressed concrete area to a triangular one, the stresses and strains are concentrated in the most compressed rib of the beams.

Fig. 8 shows the experimental diagrams of the change in the ultimate fibrous strains $\varepsilon_{\mathrm{cu}}$ of concrete as a function of the angle $\beta$ of the load plane inclination. The diagrams are constructed for all series of research beams. In this case, the beams within the same series differ only in the application angle of the external load.

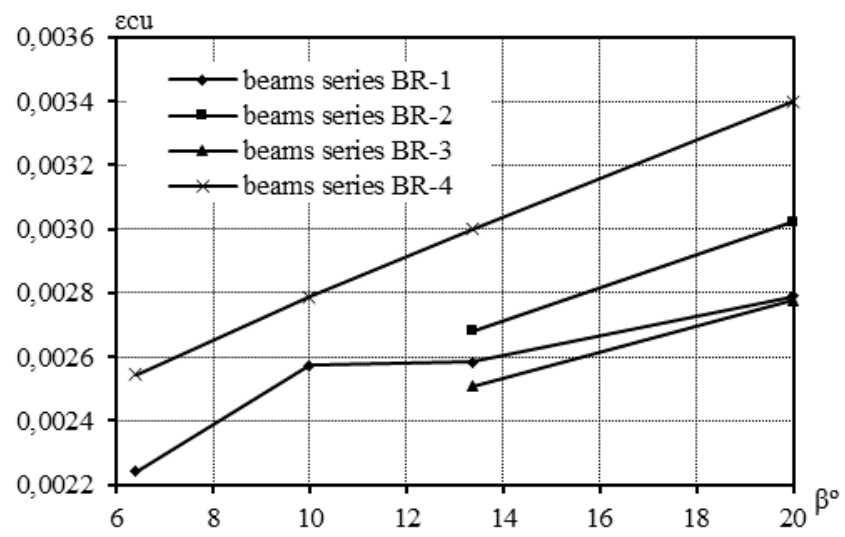

Fig. 8: Diagrams of the ultimate compressive concrete strains $\varepsilon_{\text {cu }}$ dependence on the inclination angle $\beta$ of the load plane for the series of experimental beams.

From the above-mentioned diagrams, it is seen that the increase in fibrous strains with increasing angle $\beta$ occurs in the beams of each series. In this case, the strains $\varepsilon_{\mathrm{cu}}$ reach the smallest values with the rectangular shape of the compressed concrete area and increase with the transition to the triangular shape.

Analysis of the strains of both principal and structural longitudinal reinforcement at all stages of loading makes it possible to ascertain the operation of each reinforcing bar and to reveal its effect on the stress-strain state and bearing capacity of beams.

In Fig. 9 the dependency curves of reinforcing bars strains $\varepsilon_{\mathrm{s}}$ from the action of the external moment $\mathrm{M}$ in the twin beams of the BR1 series are depicted, respectively, tested at different inclination angles $\beta$ of the load plane.

Comparing the diagrams of the strains of bar 1 for $\beta=0^{\circ}$, shown in Fig. 9, a with diagrams for the same bar at large angles $\beta$, it is established that with increasing angle $\beta$, bar 1 affects less the work of the reinforced concrete beam, and at $\beta=20^{\circ}$ it practically does not work. 
Analysing the behaviour of the strains diagrams of the tensioned bars 3, 4 and 5 in the same way, it is obvious that starting from the value $\beta=6,40^{\circ}$ with an increase in the angle $\beta$, the strains of these bars increase.
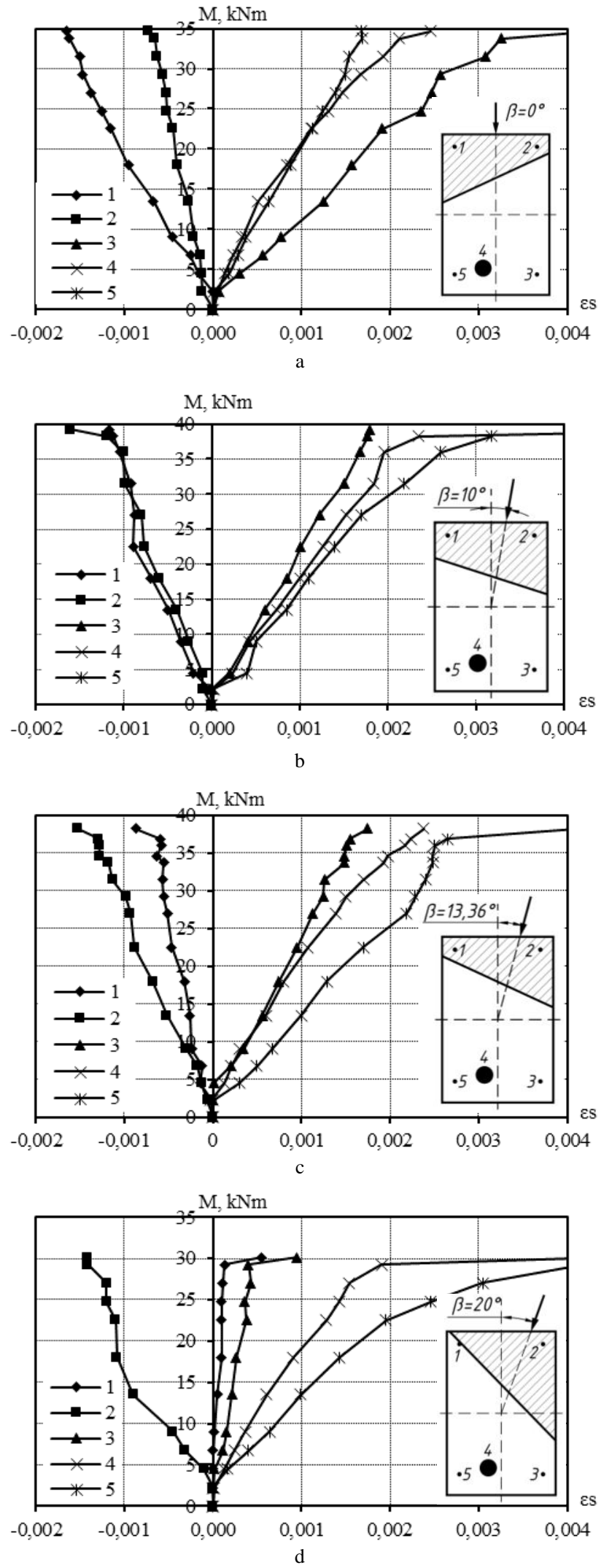

Fig. 9: Diagrams of strains of the experimental beams reinforcing bars: $\mathrm{a}-$ BR-1-1; b - BR-1-3; c-BR-1-4; d-BR-1-5.

Considering the change in the strains of bars 1 and 2, which are in the compressed area of the experimental beams section, it is easy to trace the change in the position of the neutral axis from the angle $\beta$ according to the diagrams. When comparing diagrams 1 and 2 in Fig. 9, and gradually with the diagrams 1 and 2 in Fig. 9, $\mathrm{b}, \mathrm{c}, \mathrm{d}$, it was found that the strain plot of $\operatorname{rod} 1$ with increasing $\beta$ approaches the ordinate axis, while the strain diagram of bar 2 is removed. Thus, the strains of the first bar decrease, indicating that the neutral axis approaches it and at the same time removes it from the second bar, the strains of which grow. That is, as the angle $\beta$ is increased, the neutral axis rotates clockwise, thus the inclination angle $\theta$ of the neutral axis increase.

\section{Comparative Analysis of Experimental and Theoretical Data}

The results of comparisons between the experimental and calculated values of the inclination angle $\theta$ of the neutral axis, the neutral axis depth $X$, and the strength $M_{u, \beta}$ (ultimate bending moment in the load plane inclined at an angle $\beta$ to vertical axis of inertia of the beam section) of the tested beams are given in Table 2 .

Table 2: Comparison of the results of theoretical strength calculations in the normal cross-section of biaxial bended reinforced concrete beams with experimental data

\begin{tabular}{|c|c|c|c|c|c|c|}
\hline \multicolumn{4}{|c|}{ Experimental data } & \multicolumn{3}{|c|}{ Theoretical results and deviations } \\
\hline $\begin{array}{l}\text { Sample } \\
\text { code }\end{array}$ & $\theta,{ }^{\circ}$ & $\begin{array}{c}\mathrm{X} \\
\mathrm{mm}\end{array}$ & $\begin{array}{l}\mathrm{M}_{\mathrm{u}, \beta}, \\
\mathrm{kNm}\end{array}$ & $\frac{\theta^{\circ}}{\Delta \theta}$ & $\frac{X, m m}{\Delta X}$ & $\frac{\underline{\mathrm{M}}_{\mathrm{u}, \beta}, \mathrm{kNm}}{\Delta \mathrm{M}_{\mathrm{u}, \beta}}$ \\
\hline BR-1-1 & -25.70 & 103.62 & 34.65 & $\frac{-23.05}{10 \%}$ & $\frac{95.81}{8 \%}$ & $\frac{35.65}{-3 \%}$ \\
\hline BR-1-2 & 0.00 & 74.71 & 39.60 & $\frac{0.00}{-}$ & $\frac{59.19}{21 \%}$ & $\frac{36.77}{7 \%}$ \\
\hline BR-1-3 & 13.83 & 80.59 & 39.15 & $\begin{array}{l}16.55 \\
-20 \%\end{array}$ & $\frac{85.75}{-6 \%}$ & $\frac{36.62}{6 \%}$ \\
\hline BR-1-4 & 27.09 & 99.57 & 38.25 & $\frac{28.98}{-7 \%}$ & $\frac{102.52}{-3 \%}$ & $\frac{36.01}{6 \%}$ \\
\hline BR-1-5 & 46.21 & 113.09 & 30.15 & $\frac{47.68}{-3 \%}$ & $\frac{116.91}{-3 \%}$ & $\frac{32.89}{-9 \%}$ \\
\hline BR-2-1 & 19.86 & 132.72 & 33.30 & $\frac{24.81}{-25 \%}$ & $\frac{138.67}{-4 \%}$ & $\frac{33.28}{0 \%}$ \\
\hline BR-2-2 & 41.84 & 123.67 & 32.40 & $\frac{47.07}{-12 \%}$ & $\frac{141.75}{-15 \%}$ & $\frac{31.38}{3 \%}$ \\
\hline BR-3-1 & -16.60 & 93.62 & 27.90 & $\frac{-16.92}{-2 \%}$ & $\frac{80.84}{14 \%}$ & $\frac{27.89}{0 \%}$ \\
\hline BR-3-2 & 25.34 & 88.57 & 30.15 & $\frac{28.94}{-14 \%}$ & $\frac{95.43}{-8 \%}$ & $\frac{28.18}{7 \%}$ \\
\hline BR-3-3 & 48.14 & 106.76 & 27.45 & $\frac{47.08}{2 \%}$ & $\frac{102.99}{4 \%}$ & $\frac{27.27}{1 \%}$ \\
\hline BR-4-1 & -26.58 & 116.44 & 41.40 & $\frac{-20.96}{21 \%}$ & $\frac{112.38}{3 \%}$ & $\frac{39.27}{5 \%}$ \\
\hline BR-4-2 & 1.41 & 95.53 & 42.30 & $\frac{0.00}{-}$ & $\frac{92.52}{3 \%}$ & $\frac{43.81}{-4 \%}$ \\
\hline BR-4-3 & 23.02 & 116.58 & 44.10 & $\frac{22.42}{3 \%}$ & $\frac{119.46}{-2 \%}$ & $\frac{41.76}{5 \%}$ \\
\hline BR-4-4 & 33.69 & 124.81 & 43.65 & $\frac{30.14}{11 \%}$ & $\frac{122.87}{2 \%}$ & $\frac{39.74}{9 \%}$ \\
\hline BR-4-5 & 43.46 & 141.81 & 34.65 & $\frac{42.03}{3 \%}$ & $\frac{129.68}{9 \%}$ & $\frac{31.91}{8 \%}$ \\
\hline Arithme & al mean & eviation & & 1.026 & 0.987 & 0.972 \\
\hline Root me & square & eviation & & 0.125 & 0.086 & 0.049 \\
\hline Variatio & coefficie & & & 0.122 & 0.088 & 0.051 \\
\hline
\end{tabular}

As can be seen from the obtained data, the method of strength analysis of biaxial bended elements proposed by the authors makes it possible to get sufficiently accurate values of the beams strength. The coefficient of variation with respect to the values of the bending moments is $5.1 \%$.

Good convergence of the theoretical and experimental values of the neutral axis depth $X$ and the inclination angle $\theta$ of the neutral axis should also be noted as indicated by the mean arithmetic deviation.

\section{Conclusion}

As a result of the beam samples tests under biaxial bending, the following is established: 
1. The neutral axis in the normal section of the beam during loading was moved towards the most compressed rib almost parallel if the action plane of the external load passed through the application point of the resultant in the tensioned reinforcement. If the external load plane did not coincide with the application point of the resultant, the neutral axis was rotated during the loading process.

2. The inclination angle $\theta$ of the neutral axis to the horizontal axis of the section inertia remained almost unchanged throughout the loading interval as the action plane of the external moment passed through the application point of the resultant in the tensioned reinforcement. A decrease in the angle $\theta$ during the loading process was observed in all beams in which the load plane passed to the right of the point of application of the resultant, and the increase occurred when the load plane was passed to the left.

3 . The neutral axis depth $X$ during the loading process increased in the beams tested at $\beta=0^{\circ}$, because of the displacement of the principal reinforcement from the vertical axis of section inertia. At all other values of the angle $\beta$, the neutral axis depth decreased throughout the entire load interval.

4. The ultimate fibrous compressive concrete strains in the composition of the biaxial bended beams increase with increasing the inclination angle $\beta$ of the load plane to the vertical axis of the section inertia. At the same angle $\beta$, an increase in the number and class of principal reinforcement also increases the value of the strains. At the same time, the ultimate fibrous compressive concrete strains reach the smallest values with a rectangular shape of the compressed area of concrete and increase with the transition to a triangular shape. It can be assumed that the ultimate fibrous compressive concrete strains depend on the shape of the compressed area, and not on the shape of the section.

5. Analysis of the comparison of the theoretical values of the parameters of the deformation mode and the strength of the biaxial bended reinforced concrete beams with experimental data confirms the possibility of using in practice the method of the strength analysis developed by the authors.

\section{References}

[1] J.L. Bonet, M.H.F.M. Barros, M.L. Romero, Comparative study of analytical and numerical algorithms for designing reinforced concrete sections under biaxial bending, Computers \& Structures, Vol. 84, No. 31-32, (2006), pp. 2184-2193, https://doi.org/10.1016/j.compstruc.2006.08.065.

[2] Shuenn-Yih Chang, Experimental Studies of Reinforced Concrete Bridge Columns under Axial Load Plus Biaxial Bending, Journal of Structural Engineering, Vol. 136, No 1(12), (2010), pp. 12-18, https://doi.org/10.1061/(ASCE)0733-9445(2010)136:1(12).

[3] L. Pallarés, J.L. Bonet, P.F. Miguel, M.A. Fernández Prada, Experimental research on high strength concrete slender columns subjected to compression and biaxial bending forces, Engineering Structures, Vol. 30, No 7, (2008), pp. 1879-1894, https://doi.org/10.1016/j.engstruct.2007.12.005.

[4] J.L. Bonet, M.L. Romero, P.F. Miguel, Effective flexural stiffness of slender reinforced concrete columns under axial forces and biaxial bending, Engineering Structures, Vol. 33, No. 3, (2011), pp. 881-893, https://doi.org/10.1016/j.engstruct.2010.12.009.

[5] Jin-Keun Kim, Sang-Soon Lee, The behavior of reinforced concrete columns subjected to axial force and biaxial bending, Engineering Structures, Vol. 22, No. 11, (2000), pp. 1518-1528, https://doi.org/10.1016/S0141-0296(99)00090-5.

[6] D. Yu. Sarkisov, Prochnost i deformativnost zhelezobetonnyih elementov pri kosom vnetsentrennom kratkovremennom dinamicheskom szhatii, rastyazhenii i izgibe, Vestnik Tomskogo gosudarstvennogo arhitekturno-stroitelnogo universiteta, No.3, (2008), pp. 134-143.

[7] S.S. Homon, Robota ta nesucha zdatnist kosostysnutykh zalizobetonnykh elementiv za malotsyklovykh navantazhen, Natsionalnyi universytet "Lvivska politekhnika", 2008, available online: http://ena.lp.edu.ua:8080/handle/ntb/3224.

[8] M.S. Toryanik, P.F. Vahnenko, L.V. Faleev et al, Raschet zhelezobetonnyih konstruktsiy pri slozhnyih deformatsiyah, Stroyizdat, 1974.

[9] M.S. Toryanik, L.V. Faleev, L.I. Serdyuk, Eksperimentalnoteoreticheskie issledovaniya obyichnyih i predvaritelno naprya- zhennyih zhelezobetonnyih elementov pri nekotoryih slozhnyih deformatsiyah, Stroitelnyie konstruktsii, No 19, (1972), pp. 119-124.

[10] Ye.V. Diachenko, Rozrakhunok mitsnosti kosozihnutykh zalizobetonnykh elementiv $z$ urakhuvanniam povnoi diahramy fizychnoho stanu betonu, Poltavskyi natsionalnyi tekhnichnyi universytet imeni Yuriia Kondratiuka, 2006, available online: http://www.irbisnbuv.gov.ua/cgi-

bin/irbis nbuv/cgiirbis 64.exe?C21COM=2\&I21DBN=ARD\&P21 DBN=ARD\&Z21ID=\&Image_file_name=DOC/2006/06devfsb.zip \&IMAGE FILE DOWNLOAD $=1$.

[11] M.O. Kharchenko, Rozrakhunok mitsnosti kosozihnutykh zalizobetonnykh balok tavrovoho profiliu z urakhuvanniam neliniinoho deformuvannia betonu ta armatury, Poltavskyi natsionalnyi tekhnichnyi universytet imeni Yuriia Kondratiuka, 2013, available online:https://drive.google.com/file/d/0Bwbz8yU2lkF9WVA2XzN wMUZKcjg/view.

[12] M.G. Sfakianakis, Biaxial bending with axial force of reinforced, composite and repaired concrete sections of arbitrary shape by fiber model and computer graphics, Advances in Engineering Software, Vol. 33, No 4, (2002), pp. 227-242, https://doi.org/10.1016/S09659978(02)00002-9. 